\title{
LA ANTROPOLOGÍA DE LA LITERATURA Y EL DIOSERO DE FRANCISCO ROJAS GONZÁLEZ: UNA APROXIMACIÓN
}

En el artículo se esboza una propuesta metodológica de análisis de los textos literarios a través de las teorías y de las fuentes antropológicas. Se establece el estado de la cuestión y se propone la definición de los aspectos más universales de la metodología. Dicha metodología permite considerar la antropología de la literatura como una vía que consigue estudiar no solamente los contenidos culturales de los textos, sino también localizar las modificaciones y transformaciones de los significados. Se analizará El Diosero (1952) de Francisco Rojas González como ejemplo de la literatura indigenista que encierra numerosos códigos culturales indígenas, así como muestras del pensamiento antropológico del autor marcado por el indigenismo institucional de su época. De acuerdo con la propuesta metodológica, se buscará los determinados culturemas e ideologemas, y se estudiará brevemente la figura del antropólogo, de los personajes indígenas y el recurso de la animalización de estos últimos.

Palabras clave: antropología de la literarura, literatura mexicana, siglo XX, Francisco Rojas González, El Diosero.

El Diosero, de Francisco Rojas González es una de las obras más representativas de la corriente conocida como indigenismo literario, estrechamente relacionado en México con las políticas indigenistas y modernizadoras que surgen en el país en la primera mitad del siglo XX. La antropología de la literatura constituye un recurso metodológico que permite analizar este tipo de obras - que incluyen abundantes referencias a las culturas indígenas y a la labor antropológica - con mayor profundidad. Por tanto, en primer lugar se esclarecerá brevemente la noción de la antropología de la literatura y sus premisas para posteriormente poder aplicarlas al análisis del relato. Los objetivos que persigue este artículo son los siguientes: centrarnos en la exposición del ideario indigenista del autor, revisar los culturemas presentes en la obra con el apoyo de los trabajos

\footnotetext{
*gacinska.weselina@gmail.com
} 
antropológicos de campo y detenernos en los múltiples matices que rodean la perspectiva del trabajo antropológico por parte del autor.

En la historia de la literatura hispanoamericana, las relaciones que establecen las obras literarias con el campo de la antropología resultan muy frecuentes: desde las crónicas coloniales y los relatos de viajes hasta una gran variedad de obras que giran en torno a la problemática identitaria, el mestizaje y las culturas indígenas en el siglo $\mathrm{XX}$, los contenidos antropológicos y culturales forman parte de la literatura. En cuanto al estudio de dichas obras, es preciso establecer una metodología que podría abarcar estas múltiples facetas. Según la investigadora polaca Ewa Kosowska (2007), la investigación antropológica de la literatura puede dividirse en dos vertientes: la primera de ellas, denominada como antropología cultural de la literatura, constituye un estudio de los contextos culturales y la definición de los culturemas presentes en las obras literarias, y la segunda, llamada antropología literaria, tiene como objetivo el análisis de la filosofía, ideologías y los procesos receptivos e interpretativos que acompañan la creación de las obras. Para la investigadora (Kosowska, 2007: 20), la labor de un antropólogo que se acerca a un texto literario consiste en la búsqueda y extracción de toda la información que la obra trasmite involuntariamente, ya que resulta común para su época o lugar. Las funciones estéticas de la obra y su lugar en el contexto cultural pueden, en algunos casos, prevalecer sobre su originalidad. Por tanto, «el propósito de la antropología cultural y literaria supone la identificación de este contexto y la comprensión de sus significados, valores y limitaciones» (Gacinska, 2019: 14).

El modelo cultural antropológico muestra la sujeción de la cultura a las constantes transformaciones, tanto conscientes como involuntarias, ya que los constructos culturales no permanecen inmóviles y evolucionan con el tiempo. La pluralidad de influencias en el seno de cada cultura ha sido señalada por Franz Boas, quien - como uno de los primeros - no solamente insistió en la importancia de los múltiples intercambios culturales, sino también abogó por el concepto hoy denominado como mestizaje (Gacinska, 2019: 15).

La literatura es una muestra artística de este cambio, pero también un documento del movimiento (Czapik-Lityńska, 2007: 36), ya que lo que constituye el interés primordial para el antropólogo literario son las transformaciones semióticas en el plano de la enunciación y del enunciado (Alvarado Borgoño, 2011: 71). La intensidad de estos trabajos ha aumentado recientemente, debido al desarrollo de la globalización. Como consecuencia, surgen procesos tanto sociales como culturales, tales como la hibridación cultural, la modificación de los significados tradicionales y numerosas polivalencias semióticas (Gacinska, 2019). 
Se trata entonces de un estudio de mentalidades, teniendo en cuenta los contextos históricos y culturales, así como las dinámicas sociales.

Frecuentemente se ha llamado la antención sobre la cercanía, o cierto grado de afinidad, entre los escritos literarios y la profesión antropológica de autores como José María Arguedas, Ricardo Pozas, Augusto Roa Bastos o Juan Rulfo ${ }^{1}$. La literatura hispanoamericana de medio siglo que recurre a las figuras indígenas, o que trata temas relacionados con los pueblos amerindios, ha sido calificada como literatura indigenista. Sin embargo, uno de los más destacados escritores indigenistas ${ }^{2}$, José María Arguedas, rechazaba esta denominación, constatando que la literatura no puede limitarse a una interpretación de la cultura indígena, marcada por el desconocimiento:

Siempre se habla de uno como del intérprete del indio y eso me parece muy parcial, no se puede conocer al indio si no se conoce a las demás personas que hacen del indio lo que es; solamente pueden conocer bien al indio las personas que conocen también, con la misma profundidad, a las gentes o sectores sociales que han determinado que el indio sea tal como es ahora, tal como va cambiando y evolucionando (Arguedas en Retamal, 1979: 5).

Arguedas, cuya formación antropológica y su creación literaria se entremezclaban constantemente, quizá fue uno de los autores (al lado del mexicano Ricardo Pozas) que disfrutaban de mayor «astucia humanista y la claridad etnográfica» (Orrego Arismendi, 2012b: 13). Los escritores anteriormente mencionados se dedicaban al trabajo antropológico de manera profesional o semiprofesional, incorporando ciertos elementos de sus investigaciones o trabajos de campo a su expresión artística, ya sea la literatura o la fotografía, en el caso de Juan Rulfo. Hay que tener en cuenta que, debido a la época en la que se desarrollan estos escritos, predomina la ideología política, cultural y social indigenista, que ejerció una gran influencia sobre estos autores y sus obras.

Francisco Rojas González (1904-1951) pertenecía a la vertiente de escritores-antropólogos mexicanos, cuya producción se veía fuertemente influenciada por el pensamiento indigenista oficial. Aparte de la producción literaria

\footnotetext{
${ }^{1}$ Orrego Arismendi (2012a) realiza una revisión profunda y metodológica de las relaciones entre la antropología y las letras, desde los cronistas de Indias — a través de los novelistas del siglo XIX, quienes a través de los relatos de viaje plasmaban en sus textos contenidos culturales y antropológicos - hasta la gran variedad de autores contemporáneos, cuya obra puede considerarse incluso complementaria a los estudios del campo antropológico.

${ }^{2}$ O, como lo define Orrego Arrismendi (2012b: 13), el más arquetípico.
} 
(entre sus obras merece la pena destacar la novela La negra Angustias, con la que consiguió el Premio Nacional de Literatura en 1944), Rojas González como etnógrafo colaboró en la elaboración de estudios como Atlas etnográfico de México, Estudios etnológicos del Valle del Mezquital o Los zapotecas, entre otros. Como señala Álvarez Romero, «escudada bajo la etiqueta de "ficción", la obra literaria del autor esconde implicaciones profundas sobre el proyecto modernizador mexicano que intentaba, de maneras cuestionables, "incluir" las sociedades indígenas al entonces nuevo sistema de nación» (2019: 8). Joseph Sommers (1963) insiste en situar la obra del jalisciense en el contexto nacionalista posrevolucionario y de las políticas indigenistas de las cuales el escritor fue partidario. Dentro de este contexto, el crítico enfatiza la notable presencia de lo que llama «los valores indígenas - valores tradicionales y actuales» en la narrativa de Rojas González, como fruto de los viajes y de las colaboraciones etnográficas, además de la preocupación por el proyecto nacional. Sin embargo, como acertadamente comenta Álvarez Romero (2019), la perspectiva que otorga el autor al proyecto modernizador —el lugar de los indígenas en el nuevo México posrevolucionario, así como el papel y el alcance de la antropología - no resulta uniforme. El libro de cuentos póstumo, El Diosero, constituye un vaivén de diferentes perspectivas y, en muchas ocasiones, una muestra de la debilidad de la antropología como disciplina que supuestamente permite conocer realmente al sujeto indígena: «En los cuentos hay una constante recreación del contacto cultural indígena y mestizo a través del desconcierto que crea dicho contacto desde esta última posición a la que pertenece Rojas González» (2019: 12).

Es posible enmarcar el relato «El Diosero» en lo que Lienhard (2003: 265) denomina como «etnografía ficcionalizada», ya que el texto incluye numerosas referencias culturales y etnográficas sobre las creencias y la vida familiar de los indígenas de Puná (hoy Monte Líbano) en el norte de la Selva Lacandona. El cuento narra la estancia de un antropólogo en la cabaña («champa») del cacique llamado Kai-Lan, quien vive acompañado de sus tres esposas, y a su vez, desempeña el papel de chamán. Kai-Lan, en el momento crucial del relato, durante una intensa tormenta tropical, se dedica a elaborar unas figuritas de barro que representan a los dioses que calmarían la tempestad. Los aspectos comentados en el presente trabajo se ceñirán al estudio de la figura del antropólogo, la representación indígena (de las figuras femeninas, así como del chamán-cacique) y la animalización de los personajes, así como la percepción del ritual que se lleva a cabo en la obra.

Antes de pasar al análisis del texto, es necesario realizar un inciso de corte antropológico respecto al contexto cultural y al modelo de familia representado en 
el relato. Como se ha mencionado, el cacique dispone de tres esposas, dos de las cuales trabajan durante el día y una por la noche, acompañando al diosero en su lecho. Este modelo encuentra su reflejo en los estudios etnográficos de la zona. Según señala Lucie Nečasova,

los Lacandones solían vivir en pequeños grupos familiares dispersos en la selva hasta la primera mitad del siglo XX. El matrimonio preferido era en poligamia; el hombre tenía derecho de tener más de una mujer. Las esposas solían vivir y trabajar juntas y por lo común fueron casadas cuando eran todavía pequeñas (Nečasova, 2010).

La verosimilitud de la representación de la vida familiar en la Selva Lacandona se ve reflejada también en el aspecto religioso, central en el relato de Rojas González. Sobre todo, se prohíbe la mirada de cualquiera de las mujeres de Kai-Lan en la elaboración de las figuras que pretenden aplacar a los dioses. El chamán se ve obligado a realizar varios intentos de elaboración de los artefactos debido a la presencia de las mujeres: «Cuando el lacandón se cerciora de que el ojo impuro de las hembras no mancillará la obra divina, intenta de nuevo erigirla» (Rojas González, 1972: 98). En su estudio, Nečasova (2010) confirma la primordial función del hombre en la ejecución de los rituales religiosos: «Como en muchas culturas indígenas, la participación y administración correspondía a los hombres, quienes gracias a sus oraciones y ofrendas podían comunicarse con los dioses. Las mujeres no participaban activamente y su tarea principal era la preparación de la comida sagrada». Recurriendo a las primeras páginas de este trabajo y al aspecto metodológico, en muchas ocasiones, los estudios etnográficos del campo sirven de gran ayuda no solamente en la elaboración del marco metodológico de la antropología de la literatura, sino además arrojan luz sobre los aspectos descritos en la obra, proporcionando más información, matizándola o dando pie a una polémica antropológica con los textos literarios.

En cuanto al análisis del relato, en primer lugar, destaca la relación establecida entre el científico y los personajes indígenas. El antropólogo-narrador permanece en la casa del cacique antes de dirigirse a la choza de su informante. La comunicación con Kai-Lan se lleva a cabo a través de una serie de preguntas y respuestas, siendo los enunciados del indígena cortos y sencillos, enfatizando la incapacidad del lacandón de comunicarse en español: el relato cuenta con limitadas intervenciones del cacique en castellano, siendo casi todas ellas altamente 
reiterativas $^{3}$. Ante la imposibilidad de dirigirse a la casa del informante, el antropólogo formula una pregunta acerca de la vida de la comunidad indígena, a lo que el cacique responde: « $i Y$ a ti qué te importa? ¡No hay que meterse en la vida de los vecinos!» (Rojas González, 1972: 96). Este breve fragmento demuestra la imposibilidad de la comunicación entre los dos Méxicos: el científico-modernizador y el indígena que desea permanecer apartado. Ante la reticencia de Kai-Lan a conversar con el narrador, este se limita a describir los acontecimientos, agregando una fuerte carga de subjetividad. Como señala Estelle Tarica (2002):

The self-conscious narrators these stories employ find their own position as impartial observers complicated or undone when those whom they are studying proffer resistance or implicate them in such a way as to blur the line between civilization and the primitive that underwrites the modernizing mission of the state and science among Mexico's natives (Tarica, 2002: 105) ${ }^{4}$.

Dicha dicotomía se muestra de manera implícita con la llegada de la tormenta: «En la champa nadie habla, el pavor supersticioso de los indios es menor que mis temores de hombre civilizado» (Rojas González, 1972: 97). Esta diferenciación se enfatiza también en otros momentos del relato: por ejemplo, al realizar la primera descripción del cacique, se despliega el objetivo del investigador: «A veces, cuando mi propósito logra penetrar en el cerebro o en el corazón del indio, él ríe, ríe a carcajadas» (Rojas González, 1972: 92). Lo que entonces percibe el lector no es solamente la intención de estudiar o conocer al otro, sino también la futilidad de esta tarea, consecuencia del distanciamiento con el sujeto observado. Aunque existe en el relato un breve momento de colaboración entre todos los personajes - cuando el antropólogo y las mujeres de Kai-Lan tratan

\footnotetext{
3 «Poco andarás... Viene agua, mucha agua» (Rojas González, 1972: 95), «Agua, mucha agua...», «El río, es el río» (1972: 97). En algunas ocasiones, Kai-Lan llega a referirse a sí mismo en tercera persona: «Hoy no trabaja de día Jova... A la noche sí, porque a ella toca subir a la hamaca de Kai-Lan» (1972: 104). Por desconocimiento de las lenguas lacandonas no podemos determinar si dichos enunciados se corresponden a las formas sintácticas de alguna de las lenguas indígenas de la región o únicamente constituyen una representación estereotipada de lo que popularmente se ha denominado como «hablar como indios».

4 «Los narradores conscientes empleados en estas historias encuentran complicada o deshecha su propia posición como observadores imparciales cuando aquellos a quienes están estudiando se resisten o los involucran de tal manera, que se borra la línea entre la civilización y lo primitivo que respalda la misión modernizadora del estado y ciencia entre los nativos de México». La traducción es nuestra.
} 
de salvar el huerto de los efectos destructivos de la lluvia ${ }^{5}$, la distancia real entre el investigador y los sujetos investigados se acentúa al final del cuento con el momento de la despedida: «Me dispongo a partir; regalo a las mujeres unos peines rojos y un espejo, ellas agradecen con sonrisas blancas y anchas. Kai-Lan me obsequia con un pernil de sarahuato (...). Yo correspondo con un manojo de cigarrillos» (Rojas González, 1972: 104). Dichos regalos tampoco escapan del tópico de las baratijas entregadas a los indígenas desde la época de la conquista. De alguna manera, el escaso valor y la poca utilidad de estos objetos se contradicen con los planteamientos de la política indigenista de proveer a las comunidades con lo indispensable para su modernización ${ }^{6}$.

En «El Diosero», así como en otros relatos que componen el libro, resultan frecuentes las isotopías animales. El autor recurre a la animalización de los personajes indígenas, del hombre y de las mujeres indistintamente, así como infantiliza o «empequeñece» la figura del chamán. De este modo, el personaje poderoso en su comunidad, debido a la importancia política y religiosa, en los ojos del antropólogo resulta ser un «hombrecillo» de «aspecto ridículo», que «toma una graciosa postura simiesca» (Rojas González, 1972: 92), o en otra ocasión «hincha su nariz en un husmear de bestia carnívora» (1972: 95) y «parece tapir que se revuelca entre el fango» (1972: 99). Es menester subrayar que dicho recurso se emplea en otros relatos como «La tona» o «La triste historia del pascola Cenobio», y resulta mucho más llamativo en su aplicación a las mujeres. Según Tarica (2002: 100), la exotización y sexualización de la mujer indígena son notorias en la obra del jalisciense. La investigadora señala que las mujeres suelen constituir el telón de fondo de sus textos, donde la atención recae ante todo sobre sus cuerpos, y que los retratos viscerales, y a su vez vinculados con el sexo, conducen a la idealización de lo «primitivo» en clave de la belleza. En efecto, en un contexto erótico se ofrece la siguiente descripción de una de las esposas de Kai-Lan:

La bella «kika», tal si hubiera entendido las palabras que en castellano me dijo su marido, baja los ojos ante mi curiosa mirada y pliega los labios en una sonrisa

\footnotetext{
5 «Corro a prestar auxilio a las mujeres. A poco me hallo hundido hasta la cintura en el lodo y comprometido en la lucha de los lacandones» (Rojas González, 1972: 102).

${ }^{6}$ En el relato «El cenzontle y la vereda», que transcurre en un pueblo chinanteca, el regalo como motivo también aparece con una fina capa de ironía que tiene como objetivo criticar las supersticiones indígenas frente a los logros de la ciencia. Uno de los integrantes del laboratorio antropológico establecido en el pueblo regala a una de las familias botecitos de quinina, que los indígenas, sin embargo, han decidido utilizar como collares protectores contra los malos espíritus.
} 
terriblemente picaresca. De su cuello robusto y corto, cuelga un collar de colmillos de lagarto (Rojas González, 1972: 95).

En otro fragmento se describe a la misma persona con el calificativo de una «bestecita en celo», lo que refuerza la noción de la animalización, tan común en la obra de Rojas González. De este modo, se denomina a las mujeres como «hembras» y la hija del cacique queda comparada con el cuerpo del sarahuato (mono aullador) destazado por una de las mujeres: «[una flecha] va despegándose de la carne rojiza hasta dejar un cuerpo desnudo, muy semejante en volumen y muy parecido en forma al de la indita mofletuda que llora entre los brazos de Jacinta» (Rojas González, 1972: 96). También se observa un recurso contrario: resulta notable que el sarahuato en cuestión quede antropomorfizado en los ojos del jalisciense:

el aspecto del cuadrumano es pavoroso; la cabeza caída sobre el pecho parece gesticular; sus miembros retorcidos me recuerdan imágenes de mártires sometidos a la tortura por su santidad o... por sus herejías. Los granos de sal que salpican la carne estallan con leve y enervante chasquido, al tiempo que la grasa escurre para dejar negro y enjuto el cuerpecillo antropomorfo (Rojas González, 1972: 101).

La animalización de los personajes - contrastada con la humanización del animal muerto - resulta llamativa, sin duda, en un relato que pertenece a la corriente literaria basada en la ideología que tiene entre sus principios la dignificación y valoración de las culturas indígenas. Además, en la obra de Rojas González, es posible observar una cierta ironía y burla al hablar de las tradiciones amerindias, como es el caso del cuento «La tona» y de los quehaceres de Kai-Lan.

Para aplacar la ira de los dioses y parar la tormenta, el diosero fabrica unas figuritas zoomorfas de barro. El ritual consiste en las sucesivas destrucciones de los objetos anteriormente elaborados y creación de unos nuevos, hasta que termine el huracán ${ }^{7}$. El rito finaliza con la consumición de una bebida fermentada llamada balché. En el momento de partida del antropólogo, se vuelve a mencionar los rituales en cuestión:

${ }^{7}$ Se explican las creencias de la siguiente manera: «El templo es una barraca techada con hojas de palma; sólo tiene un muro, que ve el poniente; adentro, caballetes de rústica talla y, sobre ellos, los incensarios o braserillos de barro crudo, que son deidades doblegadoras de las pasiones, moderadoras de los fenómenos naturales que en la selva se desencadenan con furia diabólica, domadores de bestias, amparo contra serpientes y sabandijas» (Rojas González, 1972: 93). 
No hay en toda la selva uno como Kai-Lan para hacer los dioses... ¿Verdad que salió bueno? Mató a la tormenta... Ve, en la pelea perdió su bonita cola de quetzal y la dejó en el cielo.

En efecto, prendido a la copa de un ramón, el arco iris esplende... (Rojas González, 1972: 104).

El cierre del relato resume varios de los aspectos que se han comentado a lo largo del artículo. En primer lugar, vuelve la idea de que tanto el diosero como el propio rito carecen de utilidad y seriedad frente a un fenómeno natural tan común en la selva como la tormenta tropical. La elaboración de los dioses ha sido en vano, ya que el fin de la tormenta y el arco iris son los resultados esperados, siendo el propio rito únicamente otra muestra de las supersticiones de los lacandones. Esto se ve necesariamente contrastado con la distribución del trabajo, en la que las mujeres y el invitado se dedican a lo «práctico» — salvar el huerto-, mientras que el diosero, obsesionado con su tarea, dedica todo el tiempo de la tempestad a elaborar las figurillas. En segundo lugar, hay que volver a destacar la despedida y la actitud paternalista y estereotipada hacia los protagonistas lacandones. El tono de la narración junto con el irónico final resumen sobremanera la actitud que toma el científico-antropólogo frente a los sujetos estudiados. La visión presentada por Rojas González no dista de otros relatos suyos incluidos en el volumen y se reduce a una crítica de las supersticiones y hechicerías de los indígenas, su ignorancia frente a los fenómenos obvios para el hombre culto y la desigual relación entre los sujetos.

A modo de conclusión, consideramos que la lectura antropológica del relato ha demostrado varias similitudes entre la ficción y la realidad etnográfica, gracias al ejercicio metodológico y el empleo de los estudios del campo. Se han encontrado y analizado varios culturemas relacionados con la religión, ritualidad y la estructura social de los lacandones que, además de aportar información cultural, han arrojado luz sobre el trabajo antropológico, sus dificultades y algunas divergencias con el pensamiento indigenista oficial. La lectura de este tipo de textos, realizada con el apoyo de la antropología literaria, permite, en primer lugar, profundizar en los contextos culturales de las etnias o lugares dibujados en la narrativa y, en segundo lugar, ofrecer una lectura crítica y analítica de los mismos. Teniendo en cuenta la distancia temporal, la politización de este tipo de textos y su función muy específica, las aproximaciones contemporáneas a la literatura indigenista permiten verla, además de su papel social y literario, como un material etnográfico y como una muestra de las mentalidades del medio siglo hispanoamericano. 
Weselina Gacinska

THE ANTHROPOLOGY OF LITERATURE AND THE DIOSERO BY FRANCISCO ROJAS GONZÁLEZ. AN APPROXIMATION

\section{Summary}

The article outlines a methodological proposal for the analysis of literary texts through anthropological theories and sources. An overview of the topic is given in the beginning and the definition of the most universal aspects of methodology is proposed. This methodology allows us to consider the anthropology of literature as a way to study not only the cultural contents of the texts, but also to locate modifications and transformations of meanings. $\mathrm{El}$ Diosero (1952) by Francisco Rojas González will be analyzed as an example of indigenous literature that contains numerous native cultural codes, as well as samples of the author's anthropological thinking. In accordance with the methodological proposal, certain culturemes and ideologemes will be sought, and the anthropologist's figure, together with the indigenous protagonists and the animalization process of the latter will be studied briefly.

Key words: Anthropology of Literature, the Mexican Literature, 20th Century, Francisco Rojas González, El Diosero.

\section{REFERENCIAS BIBLIOGRÁFICAS}

Alvarado Borgoño M. (2011). Antropología literaria. Aportes para la generación de un lenguaje intercultural. Santiago de Chile: Editorial Cuarto Propio.

Álvarez Romero A.L. (2019). «El Tona» e «Hículi Hualula» como dos visiones antitéticas sobre lo indígena en El Diosero, de Francisco Rojas González. Valenciana, 23, 7-27.

Czapik-Lityńska B. (2007). Coś więcej w literaturze niż literatura, In: Kosowska E. (ed.) (2007) Antropologia kultury - antropologia literatury. Na tropach koligacji, Katowice: Wydawnictwo Uniwersytetu Śląskiego. 27-37.

Gacinska, W. (2019). Las manifestaciones culturales de la muerte en México. La obra de Juan Rulfo, (Tesis doctoral), Universidad Autónoma de Madrid, Madrid.

Kosowska E. (2007). Kulturowa antropologia literatury. Wprowadzenie. In: Kosowska E. (ed.) (2007) Antropologia kultury - antropologia literatury. Na tropach koligacji. Katowice: Wydawnictwo Uniwersytetu Śląskiego. 17-23.

Lienhard M. (2003). La voz y su huella. Ciudad de México: Fondo de Cultura Económica. 
Nečasova L. (2010). Las mujeres lacandonas: cambios recientes. LiminaR, vol. 8, 1. Accedido el 15 de septiembre 2019, en http://www.scielo.org.mx/ scielo.php?script=sci_arttext\&pid=S1665-80272010000100006

Orrego Arismendi J.C. \& Serje M. (2012). Antropología y literatura: travesías y confluencias. Antípoda: Revista de Antropología y Arqueología, 15, 15-26.

Orrego Arismendi J.C. (2012) Literatura y antropología en América Latina: la versión de los escritores. Katharsis, 14, 11-19.

Retamal P. (1979). Literatura antropológica y antropología literaria. Letras, vol. 3, 3, 3-26.

Rojas González, F. (1972). El Diosero. México DF: Fondo de Cultura Económica.

Sommers J. (1963). La génesis literaria en Francisco Rojas González. Revista Iberoamericana, vol. 29, 56, 299-309.

Tarica E. (2002). In the Land of Broken Jugs: Francisco Rojas González and Mexican Indigenismo at Mid-Twenieth Century. Latin American Literary Review, 59, 100-121. 